Article

\title{
Empirical Study on the Factors Influencing Process Innovation When Adopting Intelligent Robots at Small- and Medium-Sized Enterprises-The Role of Organizational Supports
}

\author{
Moon Jong Choi ${ }^{1}$, Sanghyun Kim ${ }^{2, *}$ and Hyunsun Park ${ }^{2}$ \\ 1 Department of Computer Science and Engineering, Sunmoon University, 31460 Chungnam, Korea; \\ mjchoi0@gmail.com \\ 2 School of Business Administration, Kyungpook National University, 41566 Daegu, Korea; \\ sunny09@knu.ac.kr \\ * Correspondence: ksh@knu.ac.kr; Tel.: +82-53-950-5877
}

Received: 27 November 2018; Accepted: 6 December 2018; Published: 8 December 2018

\begin{abstract}
Robot technology at small- and medium-sized enterprises has become a crucial part of current business operations. Beginning with the manufacturing industry, more industries than ever before have recently begun making use of robot technology to increase operational efficiency and productivity. However, prior studies regarding innovation related to intelligent robot use have been limited to developing strategies for describing robot technologies in general. Therefore, we developed a research model for investigating process innovation as it relates to intelligent robots. Based on the literature, two variables of technology benefits (direct usefulness and indirect usefulness) and two constructs of environmental pressure (industry and government) were incorporated into the research model as key determinants of a firm's process innovation. Furthermore, organizational supports as moderating variables were added to the relationship between technology benefits and process innovation. We collected 257 responses in managerial position at various firms in order to test the proposed hypotheses using structural equation modeling in the statistical software (AMOS 22.0). The results revealed that all variables have a significant impact on process innovation, as well as the moderator. The findings of this study provide theoretical and practical implications for process innovation based on intelligent robot technology.
\end{abstract}

Keywords: intelligent robot; technology benefits; environmental pressure; organizational supports; process innovation

\section{Introduction}

In the current intelligence-based society, robots are increasingly being used to replace the human workforce. Intelligent service robots examine (perception) an external environment, judge (cognition) alternative conditions, and employ voluntary actions (mobility and manipulation). The use of intelligent service robotics and robust robot innovation processes can provide intelligent service for education, healthcare, national defense, construction, marine operations, agriculture, and many other fields [1]. Information technology (IT)-based intelligent robots represent a novel concept for robots that provide intelligent and conative services, unlike traditional robots that perform passive and repetitive tasks. Traditional robots have been classified as large industrial robots and service robots. Industrial robots, which procure raw materials for production and manufacturing purposes, are automatic adjustment devices with a multipurpose three-axis (or higher) manipulator that is fixed or automatically controlled to move and can be reprogrammed. Service robots perform useful tasks for 
humans in areas outside industrial automation applications. Industrial robots mainly perform simple and repetitive tasks, such as assembling, welding, coating, and semiconductor manufacturing, whereas service robots are largely utilized for medical purposes, animal husbandry, education, national defense, and domestic support. Recently, special service robots have been constructed to perform missions in space or deep-sea environments that are too dangerous for humans.

Many countries are pushing various policies to increase the utilization of robots. For example, The United States has promoted the "Advanced Manufacturing Partnership" (2011) and China has established a variety of robotics-related policies based on the "National long-term Science and Technology Development Plan" (2006) and implemented specific research development programs [1]. Japan has promoted a robot revolution as the core policy of its growth strategy and has large-scale national projects in progress that present long-term strategic direction for the use and proliferation of robots in the medical, social, and safety fields. Additionally, Germany intends to accelerate the automation and unmanned robot industry by announcing "Industry 4.0 " as an innovation for production systems. As the importance of robots has become increasingly clear, the world robot market has grown over 10\% annually since 2007 and has received significant attention as a high-growth market sector. Recently, rehabilitation robots that administer care to patients, educational robots that assist in providing education, and military robots that can be used for national defense have become increasingly popular. Additionally, their application range is becoming wider based on the development of new technology, but research on innovation in intelligent robot technology and processes is still lacking [2,3].

However, most previous studies on intelligent robots $[2,4,5]$ have focused on the technical aspects of intelligent robots. Such studies have not examined organizational behavior regarding intelligent robots to understand which aspects of intelligent robots lead to organizational process innovation. Furthermore, there have been few empirical studies on organizational process innovation based on intelligent robots. Therefore, this paper attempts to explain the implications of intelligent robots empirically in terms of process innovation and technological innovation introduction. Based on the literature regarding process innovation, we developed a research model that examines variables affecting innovation processes based on intelligent robots in the manufacturing sector in South Korea, which is a leading country in terms of intelligent robot adoption. Through the verification of the proposed research model, empirical answers to the following three research questions were obtained.

(1) How many intelligent robot technologies are being used to innovate processes in organizations?

(2) Do technology context, organization context, and environment context (TOE) elements have a positive impact on organizational process innovation based on intelligent robot technologies?

(3) Does organizational support enhance the relationship between technical traits and process innovation based on intelligent robot technologies?

To determine the answers to these questions, the proposed research model includes two variables (direct usefulness and indirect usefulness) for technical traits and two variables (industry pressure and governmental pressure) for environmental pressure. Additionally, organizational supports are proposed as a moderating effect for the relationship between the variables of technical traits and process innovation based on intelligent robots. Validation of the proposed research model is expected to improve our understanding of the reasons why firms adopt intelligent robots to improve their processes.

\section{Related Works and Hypotheses}

\subsection{Process Innovation}

Research on the performance and behavioral aspects of intelligent robots at the enterprise level is lacking compared to technical research on robots. Furthermore, even after adopting and developing robot technologies, the impact of innovative technology on processes and performance 
has not clearly been studied. Following Schumpeter's [6] research, various studies on the impact of innovative activities on the performance of companies have been conducted $[7,8]$. Innovation is a multidimensional concept that includes changes to products, changes to organizational aspects based on new technologies, policies, and the restructuring of organizational culture, and changes to manufacturing processes. Innovation can also refer to technological innovation, process innovation, and management innovation, as well as other aspects of production, all of which aim to achieve improved competitiveness and performance through innovation in terms of overall management, processes, organizational culture, products, and services. Knight [9] divided innovation into product innovation, process innovation, structural innovation, and people innovation, whereas Damanpour [7] divided innovation into technological innovation and administrative innovation. Barney and Griffin [10] specified that management innovation focuses on management processes while technology innovation often occurs in products and processes.

Intelligent robots have already been implemented in real business enterprises and used in the development and manufacturing processes of products and services. Therefore, such robots are suitable for process innovation because they allow companies to focus on new processes for the production of products and services. Process innovation refers to a company performing a process in new ways. In particular, it involves specific changes related to manufacturing processes and technology [11]. In other words, process innovation can include the introduction of new methods or processes within an enterprise and the variation of methods to create products or provide services [11,12]. In fact, process innovation is similar to the concept of management innovation, which includes business processes and organizational policies, unlike technology innovation, which includes new technologies, products, and services [7]. Innovations in robotics facilitate process innovation and have a positive effect on the innovation performance of a company. In general, the introduction of new innovative technologies is as an essential element in business innovation because process innovation is a major part of business innovation [8]. Therefore, this study focused on process innovation and examined the impact factors of innovation processes as they relate to the introduction of intelligent robots.

\subsection{TOE Framework}

In a study on organizational innovation processes, Tomatzky and Fleischer [13] proposed a division of the factors influencing technological innovation into three contexts, namely the technology context, organization context, and environment context, called the TOE framework. The technological context pertains to technical characteristics that affect the introduction of new technologies in an organization, including characteristics both inside and outside the technology. This includes not only existing technologies, but also all available technologies that can be introduced to the market in the future. Next, the organization context refers to the property and resources of an organization that facilitate or restrict the introduction of innovations. This includes the size of the organization, management structure, quality of human resources, degree of centralization, formalization, complexity of management organization, and internal communication [14]. Finally, the environmental context refers to the activity area in which an organization performs business activities. It includes the structure and scale of the industry to which the organization belongs, competitors, resource providers, and governments or regulatory environments. The TOE framework describes the manner in which organizations identify and introduce new technology and processes from these three perspectives.

As several empirical studies have verified the effectiveness of the TOE framework on a variety of ITs, such as electronic data interchange (EDI), enterprise resource planning (ERP), and radio frequency identification (RFID), the TOE framework has been widely adopted as a useful model for providing predictive power regarding the factors affecting the introduction and spread of technological innovations [14-16]. For example, Iacovou et al. [15] divided the factors affecting EDI acceptance into three levels, namely organization, external force, and perceived benefit, and verified their model through seven case studies. Chau and Tam [16] used the TOE framework in their study to examine the factors affecting the introduction of the Open Systems software by conducting one-on-one interviews 
with 89 companies. They stated that the TOE framework can be a useful starting point for examining the impact factors of the Open Systems software because it can highlight the specific circumstances that influence the process of technology adoption. Additionally, Kuan and Chau [17] developed a research model and proposed an empirical analysis method based on the TOE framework that included technical characteristics (perceived direct benefit and perceived indirect benefit), organizational characteristics (perceived economic cost and perceived technical competence), and environmental characteristics (perceived industry pressure and perceived governmental pressure). These factors were found to affect the introduction of EDI (with the exception of perceived indirect benefit) and the TOE framework was highlighted as a useful theoretical framework for examining the major factors influencing decisions regarding the introduction of IT.

Yoon and George [18] examined and divided the factors influencing virtual reality acceptance at an organizational level based on the TOE framework. These factors included technical characteristics (relative advantage, compatibility, and security concerns), organizational nature (support of top management, company size, organizational readiness, business scope), and business environment (imitation of competitor pressures, customer force pressure, normative pressures, and competitive strength). The results showed that organizational readiness, imitation of competitor pressures, and normative pressures have a significant influence on the accommodation of technological innovation. Lin [19] used the TOE framework to examine the determinants of the introduction of supply chain management (SCM) systems. This study focused on technical characteristics (perceived benefits and perceived costs), organizational characteristics (firm size, support from top management, and absorptive capacity), and environmental characteristics (trading partners affected and competitive pressures) as key determinants for implementing SCM. The study results show that perceived benefits, perceived costs, support from top management, absorptive capacity, and competitive pressures were significant factors affecting the introduction of SCM.

Therefore, the TOE framework can be a useful model for providing the empirical explanations discussed in the introduction, as well as analyzing the spread of new technology [16,20]. In particular, the TOE framework has been highlighted as a theoretical model of value because it can be implemented for various techniques, organizations, and environmental factors in accordance with IT research, showing excellent potential for generalization [21]. In the context of intelligent robots, it is not limited to simple routine tasks in existing simple manufacturing processes, but can also be applied to combinations of IT networks and mechanisms. By applying the TOE framework to the introduction of IT and a generalized model of its spread, the framework can be utilized by various enterprises as a useful tool for explaining technological innovation through the introduction of intelligent robots. However, process innovation in companies using intelligent robots emphasizes the importance of technical and environmental factors among the various TOE framework elements. This is because the technical benefits of using intelligent robots and the environmental factors in an organization are more important than the tendencies of organizational managers [21]. Therefore, this study focused only on the technology and environment characteristics of the TOE framework.

\section{Research Model and Hypotheses}

\subsection{Research Model}

Figure 1 presents the proposed research model and hypotheses. Based on the original TOE framework, we conducted a survey to develop this research model. For the proposed model, a survey reflecting the technological benefits and environmental pressures that may play important roles in process innovation based on intelligent robots was administered from the perspective of organizational members by conducting interviews with managers and staff members, and using a basic research model based on a literature review. Therefore, this study included technological benefits and environmental pressures as the key factors influencing an organization's process innovation based on intelligent robots. 


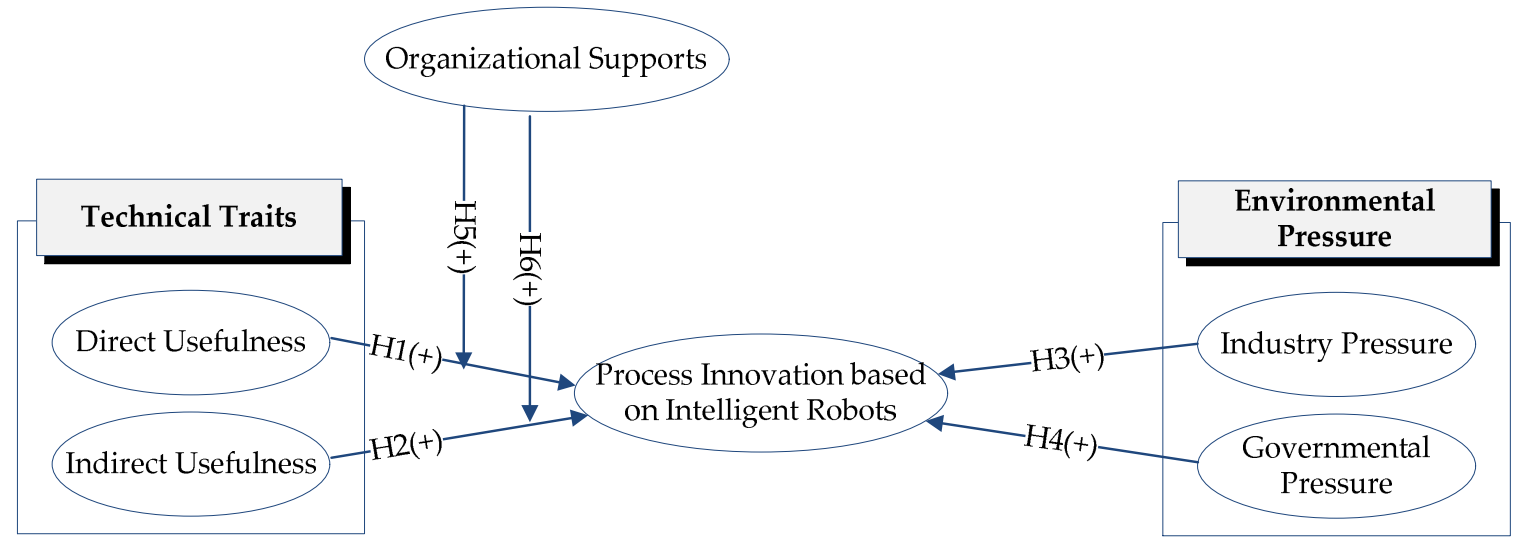

Figure 1. Research model and hypotheses.

\subsection{Hypothesis Development}

The technological characteristics (technology context) in the TOE framework are associated with the attributes of innovation related to IT consumers. We propose the factors of the direct usefulness and indirect usefulness of recognizing an organizational standpoint regarding intelligent robots as technological characteristics [17]. Perception of usefulness has been recognized as an important factor in an organization's perception of the relative benefits that a particular technology can provide, leading to process innovation through that technology $[15,22]$. These perceived benefits are related to multiple variables and concepts, such as usefulness and advantages in IT-related research. Perceived benefits were largely used in this study to measure the extent an individual's cognition of IT as the degree of belief that the use of a specific technology or system will improve business performance [23]. Other studies $[14,17,21]$ have defined perceived benefits as the extent of cognition of the performance impacts of an organization using IT at an organization level. In this study, we classified the benefits of using specific technologies as direct and indirect benefits [15], and examined the effects of these two types of benefits on process innovation based on intelligent robots.

First, direct usefulness refers to detection of direct changes in the degree of a company's process innovation to recognize and increase the accuracy, efficiency, and speed of work by utilizing intelligent robots [17]. Intangible benefits and reduction of operating costs, such as price transparency and accessibility improvements for customers, are also related to direct usefulness. In contrast, indirect usefulness involves the detection of indirect changes in corporate innovation processes by using intelligent robots for improvement of the competitiveness and image of an organization, service enhancements for customers, and better relationships with suppliers. In other words, business process management and the factors affecting the customer relationships of organization are associated with indirect usefulness.

Many previous studies have emphasized the importance of these two types of usefulness in organizational process innovation. Furthermore, prior studies examining the beneficial relationships between these two types of usefulness and IT adoption have found that direct usefulness is largely related to operational reduction as it pertains to an organization's internal efficiency, whereas indirect usefulness is largely related to technological and competitive advantages. Additionally, it has been found that the degree of new IT direct and indirect usefulness has a positive effect on the acceptance of IT and integration of existing technologies [24,25]. Therefore, based on these claims, we propose the following research hypotheses:

Hypothesis 1. Direct usefulness is positively associated with process innovation based on intelligent robots.

Hypothesis 2. Indirect usefulness is positively associated with process innovation based on intelligent robots. 
Environmental characteristics (environment context) are related to environmental factors that affect corporate business activities from the outside, such as pressure, competition, and uncertainty $[13,16,17]$. Because environmental factors are often difficult to control for an organization, they are perceived as critical to organizational process innovation [19]. We propose industry pressure and governmental pressure as two types of environmental pressure affecting process innovation based on intelligent robots.

First, industry pressure refers to the pressure caused by the demands and circumstances of business partners or competitors, such as trading companies [22,25]. If business partners or competitors within an industry introduce new IT, companies actively introduce and use similar or competitive technology to gain a competitive advantage. In other words, as the percentage of competitors adopting new technology or innovations within an industry increases, industry pressure will increase with the introduction of IT, which will have a significant impact on enterprises that are making decisions related to the introduction of IT and intending to pursue innovation. Therefore, industry pressures play an important role in driving organizational technology and process innovation [2].

Second, governmental pressure refers to government policies or normative pressures on the introduction of advanced technologies, such as IT or robotics [2]. The emphasis on the role of the government is important in the process of computerization promotion because a government can induce technology vitalization and facilitate the introduction of technology by proposing associated policies and guidelines when new ITs emerge. For example, the US government announced the "Advanced Manufacturing Partnership" (2011) as a part of its national robotics initiative and is currently pursuing the introduction and utilization of advanced robots in manufacturing. South Korea announced the first intelligent robot basic plan in 2009 and second basic plan in 2014. Additionally, South Korea has promoted intelligent robot activity by introducing a robot supply business, which involved creating a legal basis for the robot specialist designation through intelligent robot development and dissemination promotion in 2012 [1]. Such changes to national policy regarding innovations, such as robots, are recognized as another pressure on organizations and that leads to process innovation.

Additionally, prior studies examining the relationships between external pressure and both technical and process innovation have confirmed that corporate partners, competitors, and governmental pressure all affect the introduction of new technologies, such as EDI, ERP, and RFID [24]. Zhu et al. [25] claimed that firms tend to accommodate techniques based on the strength of incoming pressure for the introduction of new technologies when competition in the industry is intensified. Kuan and Chau [17] found that various pressures, such as government policies or regulations, have a significant impact on corporate innovation. Based on these claims, we propose the following two hypotheses:

Hypothesis 3. Industry pressure is positively associated with process innovation based on intelligent robots.

Hypothesis 4. Governmental pressure is positively associated with process innovation based on intelligent robots.

\subsection{The Moderating Effect of Organizational Supports}

In this study, organizational support was defined as the degree of environment creation, education, monetary and technical support, and encouragement of use through which organizations are prepared and persuaded to achieve their expected performance via process innovation based on robotics [26]. In previous studies on IT, it has been argued that appropriate support and related activities at the organizational level have a positive effect on organizational acceptance of new technologies, use behaviors, and organizational process innovations [26,27]. This is because organizational support can motivate members to concentrate on their roles through their efforts in various situations and actively motivate them to use IT when they wish to implement IT successfully in an organization.

Organizational support is a factor that directly affects technology acceptance, but also serves as a controlling variable in the relationship between independent and dependent variables [26]. Lee et al. [26] explained that organizational support plays a key role as a control variable in the relationship between the usefulness of IT and intention to use IT. Malhotra, Heine, and Grover [28] 
explained that by providing sufficient resources to organization members through organizational support, members can increase the level and use of new IT. Robotics may also require appropriate organizational support to create process innovation, such as increased satisfaction or performance when using such technology, and appropriate support can strengthen the relationship between robot technology advantages and organizational process innovation. Therefore, we propose organizational support as a control variable to strengthen the relationship between intelligent robot technology advantages and process innovation based on the above discussion, and propose the following hypotheses to examine its role.

Hypothesis 5. Organizational support will strengthen the relationship between direct usefulness and process innovation based on intelligent robots.

Hypothesis 6. Organizational support will strengthen the relationship between indirect usefulness and process innovation based on intelligent robots.

\section{Methodology and Analysis}

\subsection{Samples}

Data collection for this study involved selecting small and medium-sized enterprises (SMEs) that have introduced intelligent robots and contacting enterprise representatives for survey responses. Online survey questionnaires were sent to the representatives at various firms, and 269 responses from managerial positions were obtained. However, 12 responses were discarded because of missing values. Therefore, 257 responses were used for analysis. Since all responses are collected from the manager position, there is no problem with the representation of the data. Regarding the demographic information of the participants surveyed, 164 were male and 93 were female. Participants were diverse in age, ranging from 30 years to more than 50 years, with 47 years being the average age. All participants are were in management positions: $36.58 \%$ were CIOs/CFOs, $29.96 \%$ were CEOs, $26.85 \%$ were senior managers, and $5.06 \%$ were associate managers. Additionally, the industrial distribution of participants was surveyed. Automotive was the highest at $32.30 \%$, followed by metal/machinery $(19.46 \%)$, semiconductor $(17.12 \%)$, shipping/aerospace $(15.18 \%)$, and energy $(11.28 \%)$. Therefore, the participants were involved in a variety of industries, implying that robotics are being used in various industries. Furthermore, by using data collected from various industries for analysis, the problem of generalization of research results was minimized.

Finally, the participants in the survey used robot technology for various purposes. Among the participants, $68.48 \%$ answered that they use robot technology for production efficiency, followed by operational effectiveness $(47.86 \%)$, improvement of work environments $(39.30 \%)$, and cost savings $(32.68 \%)$. Table 1 lists the profiles of the respondents.

Table 1. Demographic characteristics $(n=257)$.

\begin{tabular}{cccc}
\hline & Demographic Categories & Frequency & Percentage \\
\hline \multirow{2}{*}{ Gender } & Male & 164 & $63.81 \%$ \\
& Female & 93 & $36.19 \%$ \\
\hline \multirow{3}{*}{ Age (years) } & $30-39$ & 51 & $19.84 \%$ \\
& $40-49$ & 126 & $49.03 \%$ \\
& $50+$ & 80 & $31.13 \%$ \\
\hline \multirow{4}{*}{ Job Title } & CEO & 77 & $29.96 \%$ \\
& CIO/CFO & 94 & $36.58 \%$ \\
& Senior Manager & 69 & $26.85 \%$ \\
& Associate Manager & 13 & $5.06 \%$ \\
& Other & 4 & $1.56 \%$ \\
\hline
\end{tabular}


Table 1. Cont.

\begin{tabular}{|c|c|c|c|}
\hline \multicolumn{2}{|c|}{ Demographic Categories } & Frequency & Percentage \\
\hline \multirow{6}{*}{ Industry } & Automotive & 83 & $32.30 \%$ \\
\hline & Metal/Machinery & 50 & $19.46 \%$ \\
\hline & Shipping/Aerospace & 39 & $15.18 \%$ \\
\hline & Semiconductor & 44 & $17.12 \%$ \\
\hline & Energy & 29 & $11.28 \%$ \\
\hline & Other & 12 & $4.67 \%$ \\
\hline \multirow{5}{*}{$\begin{array}{l}\text { Purpose of Using } \\
\text { Intelligence Robot } \\
\text { (multiple responses) }\end{array}$} & Production Efficiency & 176 & $68.48 \%$ \\
\hline & Operational Effectiveness & 123 & $47.86 \%$ \\
\hline & Cost Savings & 84 & $32.68 \%$ \\
\hline & Improvement of Work Environments & 101 & $39.30 \%$ \\
\hline & Other & 10 & $3.89 \%$ \\
\hline
\end{tabular}

\subsection{Development of Measures}

The development of the items to be used for verification of the proposed research model was performed in three stages. First, items that have proved their validity through theoretical background studies were investigated, revised, and supplemented appropriately. Second, after the questionnaire items were reorganized based on interviews with business people who lead process innovation based on robot technology, the final measurement items to be used for further analysis were developed. Finally, to verify the statistical validity of the developed measurement items, we conducted a pilot test on companies using robot technology for various company activities and companies with robot technology implementation plans. As a result of our preliminary investigation, it was found that there are no factors that hinder the reliability or validity of the measurement items. The final questionnaire items that were derived to measure each variable in the study model were evaluated using a 7-point Liker scale ranging from (1) "strongly disagree" to (7) "strongly agree." Table 2 lists the final measures that were developed and used to assess each construct and their related studies.

Table 2. Constructs and related studies.

\begin{tabular}{|c|c|c|}
\hline Construct & Measures & Related Studies \\
\hline Direct Usefulness & $\begin{array}{l}\text { - } \quad \text { The accuracy of work has increased. } \\
\text { - } \quad \text { Work efficiency has increased. } \\
\text { - } \quad \text { Production speed has improved. } \\
\text { - The defect rate of the product has decreased. }\end{array}$ & $\begin{array}{c}\text { Venkatesh and Davis [29], } \\
\text { Igbaria et al. [30] }\end{array}$ \\
\hline Indirect Usefulness & $\begin{array}{l}\text { - The corporate image has improved. } \\
\text { - The companys competitiveness has improved. } \\
\text { - } \quad \text { Other business opportunities have increased. } \\
\text { - Customer service has improved. }\end{array}$ & $\begin{array}{c}\text { Venkatesh and Davis [29], } \\
\text { Igbaria et al. [30] }\end{array}$ \\
\hline Industry Pressure & $\begin{array}{l}\text { Business partners (suppliers, customers, etc.) } \\
\text { had to adopt intelligent robots. } \\
\text { There was a demand for the introduction of } \\
\text { intelligent robots by major companies. } \\
\text { Major competitors will soon adopt } \\
\text { intelligent robots. } \\
\text { - Core competitors will adopt intelligent robots. }\end{array}$ & Hsu et al. [31] \\
\hline Governmental Pressure & $\begin{array}{l}\text { The government has increased its obligations } \\
\text { and regulations regarding the use of } \\
\text { intelligent robots. } \\
\text { There is a business area where automation } \\
\text { must be implemented with obligatory } \\
\text { intelligent robots. } \\
\text { Government requirements for the use of } \\
\text { intelligent robots have been strengthened. }\end{array}$ & Liang et al. [32] \\
\hline
\end{tabular}


Table 2. Cont.

\begin{tabular}{|c|c|c|}
\hline Construct & Measures & Related Studies \\
\hline Organizational Supports & $\begin{array}{l}\text { - Our organization provides a variety of } \\
\text { supports for process innovation. } \\
\text { - Our management team supports the budget } \\
\text { for adopting and maintaining } \\
\text { intelligent robots. } \\
\text { - Our organizational management team } \\
\text { formulated process innovation using new } \\
\text { intelligent robots in production processes as } \\
\text { an organizational IT strategy. }\end{array}$ & $\begin{array}{c}\text { Lee et al. [26], } \\
\text { Malhotra et al. [28] }\end{array}$ \\
\hline $\begin{array}{l}\text { Process Innovation based on } \\
\text { Intelligent Robots }\end{array}$ & $\begin{array}{l}\text { - Our company develops new products quickly. } \\
\text { - } \quad \text { Our company has high } \\
\text { production competitiveness. } \\
\text { Our company is adopting the latest } \\
\text { technology into its product processes. } \\
\text { - Our company is fast to apply the latest } \\
\text { technology to product processes. } \\
\text { - Our company continuously strives to develop } \\
\text { new products and services. }\end{array}$ & $\begin{array}{l}\text { Knight [9]. } \\
\text { Lazarus and Novicoff [33] }\end{array}$ \\
\hline
\end{tabular}

\subsection{Analysis of the Measurement Model}

Before analyzing the structural model, the measurement model was verified in terms of the reliability and validity of each latent variable for measuring observed variables. The partial least squares (PLS) approach was used in this study because it is a distributed structural equation method that can be used when there are a small number of samples, as was the case in this study. The main tool used for analysis was SmartPLS 2.0. First, Cronbach's alpha for each construct was calculated to measure reliability. The criteria for reliability is an alpha value of at least 0.7 [34].

Next, two types of validity were analyzed: convergent validity and discriminant validity. Convergent validity is used to verify the degree of correlation between a variable to be measured and the latent variables related to the same concept. In contrast, discriminant validity is used when measuring different concepts and correlation between obtained measured values should be relatively low. Several indices, such as the factor loading of each item, average variance extracted (AVE), and composite reliability (CR), were used to measure convergent validity. The threshold for factor loading and CR was 0.7 or greater and AVE should be greater than 0.5 for each latent variable [3]. As shown in Table 3, all loadings, AVE, CR, and Cronbach's alpha values were greater than the minimum acceptable value, implying that there were no major issues in terms of the reliability and validity of the measurement model.

Table 3. Results for reliability and convergent validity.

\begin{tabular}{cccccc}
\hline Latent Construct & Item & Factor Loading & CR & AVE & Cronbach's Alpha \\
\hline \multirow{3}{*}{ Direct Usefulness } & $\mathrm{du} 1$ & 0.813 & & & \\
& $\mathrm{du} 2$ & 0.932 & 0.932 & 0.776 & 0.835 \\
& $\mathrm{du} 3$ & 0.856 & & & \\
& $\mathrm{du} 4$ & 0.917 & & & 0.841 \\
Indirect Usefulness & $\mathrm{iu} 1$ & 0.909 & & \\
& $\mathrm{iu2}$ & 0.829 & 0.950 & 0.827 & \\
& $\mathrm{iu} 3$ & 0.952 & & & \\
& $\mathrm{iu} 4$ & 0.943 & & & \\
\hline \multirow{2}{*}{ Industry Pressure } & $\mathrm{ip} 1$ & 0.927 & & & \\
& $\mathrm{ip} 2$ & 0.882 & 0.944 & 0.808 & \\
\hline
\end{tabular}


Table 3. Cont.

\begin{tabular}{|c|c|c|c|c|c|}
\hline Latent Construct & Item & Factor Loading & CR & AVE & Cronbach's Alpha \\
\hline \multirow{3}{*}{ Governmental Pressure } & gp1 & 0.814 & \multirow{3}{*}{0.898} & \multirow{3}{*}{0.746} & \multirow{3}{*}{0.869} \\
\hline & gp2 & 0.949 & & & \\
\hline & gp3 & 0.822 & & & \\
\hline \multirow{4}{*}{ Organizational Supports } & os1 & 0.907 & \multirow{4}{*}{0.911} & \multirow{4}{*}{0.718} & \multirow{4}{*}{0.890} \\
\hline & os2 & 0.802 & & & \\
\hline & os3 & 0.846 & & & \\
\hline & os4 & 0.832 & & & \\
\hline \multirow{5}{*}{$\begin{array}{l}\text { Process Innovation based } \\
\text { on Intelligent Robots }\end{array}$} & pi1 & 0.782 & \multirow{5}{*}{0.920} & \multirow{5}{*}{0.696} & \multirow{5}{*}{0.807} \\
\hline & pi2 & 0.825 & & & \\
\hline & pi3 & 0.858 & & & \\
\hline & pi4 & 0.891 & & & \\
\hline & pi5 & 0.812 & & & \\
\hline
\end{tabular}

Finally, discriminant validity was verified by comparing the square root of the AVE and correlation coefficient values for each latent construct proposed in the research model. To demonstrate discriminant validity, the square root of the AVE for each construct should be larger than the correlation values of the longitudinal and transverse elements. As shown in Table 4, the values on the diagonal (square root of AVE) are greater than all correlation values of the longitudinal and transverse elements, implying that the discriminate validity of the measurement model was not an issue in this study.

Table 4. Discriminant validity test.

\begin{tabular}{|c|c|c|c|c|c|c|}
\hline Latent Construct & (1) & (2) & (3) & (4) & (5) & (6) \\
\hline (1) Direct Usefulness & 0.881 & & & & & \\
\hline (2) Indirect Usefulness & 0.310 & 0.910 & & & & \\
\hline (3) Industry Pressure & 0.208 & 0.343 & 0.899 & & & \\
\hline (4) Governmental Pressure & 0.297 & 0.216 & 0.364 & 0.864 & & \\
\hline (5) Organizational Supports & 0.200 & 0.315 & 0.267 & 0.344 & 0.848 & \\
\hline (6) Process Innovation based on Intelligent Robots & 0.217 & 0.278 & 0.360 & 0.292 & 0.368 & 0.834 \\
\hline
\end{tabular}

\subsection{Structural Model Assessment}

Causality validation for each route suggested in the research model was performed using the PLS approach and structural model analysis. First, the two variables (direct usefulness and indirect usefulness) of technology benefits had a positive impact on process innovation based on intelligent robots. Direct usefulness had a path coefficient of 0.359 and $t$-value of 4.905 . Indirect usefulness had a path coefficient of 0.296 and $t$-value of 3.887. Therefore, $\mathrm{H} 1$ and $\mathrm{H} 2$ were supported with a significance level of 0.01 . Direct usefulness had a greater impact on process innovation than indirect usefulness. In other words, important factors for process innovation based on the adoption of intelligent robots are the direct benefits derived from intelligent robots (e.g., productivity improvement and business process improvement).

Additionally, the two variables (industry pressure and governmental pressure) of environmental pressure were found to be significant for process innovation based on intelligent robots. The standardized path coefficient of industry pressure was 0.415 with a $t$-value of 7.062. Governmental pressure had a path coefficient of 0.242 with a $t$-value 4.107. Therefore, $\mathrm{H} 3$ and $\mathrm{H} 4$ were supported with $p<0.01$. If process innovation based on intelligent robots takes place within the industry in which a firm is involved, it can be observed that the firm has no choice but to perform process innovation. Additionally, these results imply that when governments create policies regarding process innovation based on intelligent robots, organizations are under increased pressure to innovate their processes to keep pace with government policy, which forces them to perform process innovation based on intelligent robots. 
The moderating effect of organizational supports was evaluated by calculating an interaction term, which is a commonly used approach in the literature [35]. First, organizational support has been shown to strengthen the relationship between direct usefulness and process innovation based on intelligent robots. Therefore, $\mathrm{H} 5$ was supported. This result implies that process innovation in an organization based on intelligent robots can be more successful if various organizational supports, such as budgeting and management, are added to the direct usefulness of the intelligent robots. Prior studies $[26,27,35]$ have claimed that organizational or (top) management support plays a crucial role in implementing various technology-based projects and activities. Similar results were also found in the relationship between indirect usefulness and process innovation based on intelligent robots. The standardized path coefficient was 0.211 with a $t$-value of 2.981 , which was significant at $p<0.01$. This result shows that indirect usefulness, such as organizational reputation, competitiveness, new business opportunities, and customer service improvement, which can be derived from the adoption of intelligent robots, can be helpful for process innovation. If organizational support is added, then innovation is even more effective. Finally, the analysis results show that all the proposed external variables account for $59.3 \%$ of the variance in process innovation based on intelligent robots, implying that $59.3 \%$ of information process innovation based on intelligent robots is determined by four variables. Figure 2 presents our structural model analysis and Table 5 summarize the results of hypothesis testing.

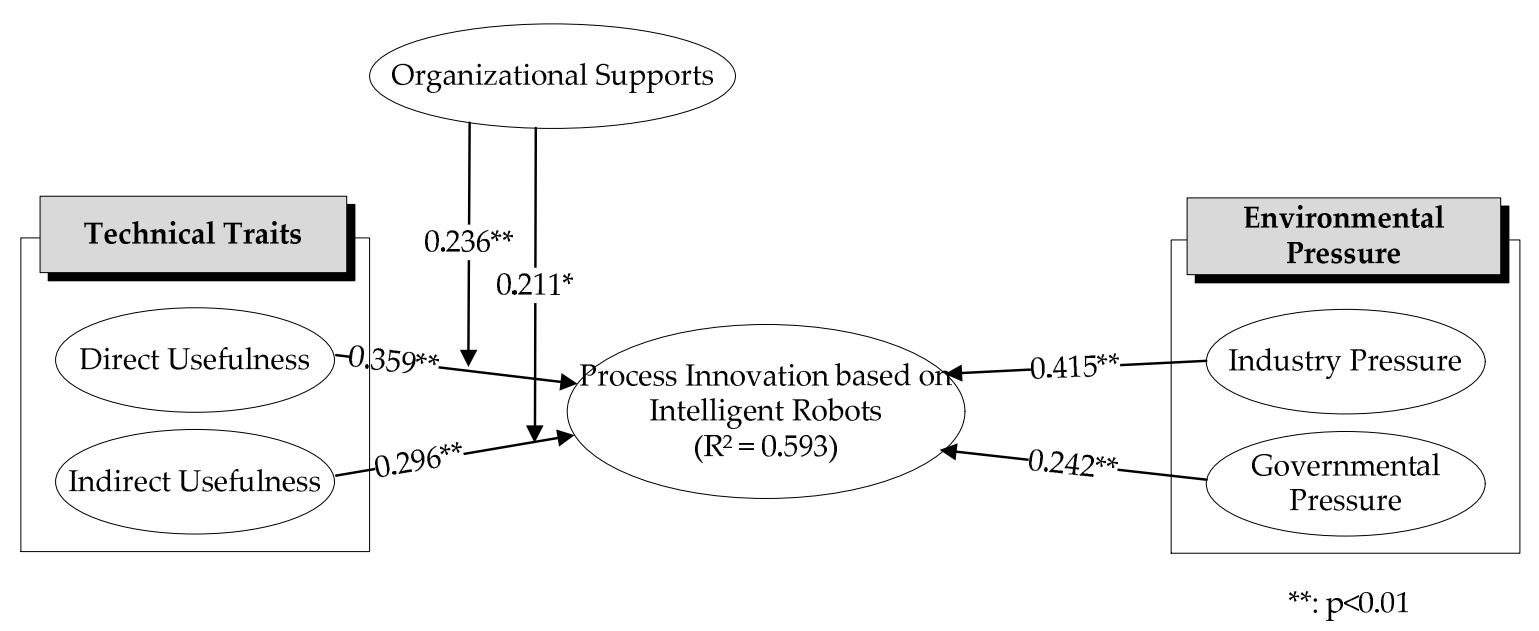

Figure 2. Results of the structural model.

Table 5. Summary of hypothesis tests (H1-H6).

\begin{tabular}{|c|c|c|c|c|c|c|}
\hline Hypothesis & & Path & & Std. $\beta$ & $t$-Value & Result \\
\hline $\mathrm{H} 1$ & Direct Usefulness & \multirow{4}{*}{$\rightarrow$} & \multirow{4}{*}{$\begin{array}{l}\text { Process Innovation based } \\
\text { on Intelligent Robots }\end{array}$} & 0.359 & 4.905 & $S^{* *}$ \\
\hline $\mathrm{H} 2$ & Indirect Usefulness & & & 0.296 & 3.887 & $S^{* *}$ \\
\hline H3 & Industry Pressure & & & 0.415 & 7.062 & $S^{* *}$ \\
\hline $\mathrm{H} 4$ & Governmental Pressure & & & 0.242 & 4.107 & $S^{* *}$ \\
\hline \multicolumn{7}{|c|}{ Moderating Effects } \\
\hline \multirow[b]{2}{*}{ H5 } & Direct Usefulness & & \multirow{3}{*}{$\begin{array}{l}\text { Process Innovation based } \\
\text { on Intelligent Robots }\end{array}$} & & & \\
\hline & $\begin{array}{c}\mathrm{x} \\
\text { Organizational Supports } \\
\text { Indirect Usefulness }\end{array}$ & $\rightarrow$ & & 0.236 & 3.338 & $S * *$ \\
\hline H6 & $\begin{array}{c}\mathrm{x} \\
\text { Organizational Supports }\end{array}$ & & & 0.211 & 2.981 & $S^{*}$ \\
\hline
\end{tabular}

Note: ${ }^{*}: p<0.05 ;{ }^{* *}: p<0.01 ;$ S: Supported.

\section{Conclusions and Implications}

IT is at the forefront of technological innovation, as indicated by smartphone usage and internet-powered keywords, such as artificial intelligence, robots, internet of things (IoT), and big 
data [2]. In particular, the rapid development of IoT technology has accelerated the commercialization of intelligent robots. Powerful ripple effects spread to mechanical parts, electronics, software, controls, communications, and materials in convergent applications, such as the automotive industry, consumer electronics, and smart home technology. This study adopted the TOE framework in the context of intelligent robots when a firm attempts to implement process innovation. Empirical analysis was carried out to target SME employees of companies using intelligent robots to innovate processes. The data for this study were collected from 257 respondents, who were in charge of businesses introducing intelligent robots. The results of this study are as follows.

First, the direct and indirect usefulness of technological benefits had a positive impact on the innovation process. These results imply that positive effects, such as improved efficiency and production speed, and accuracy based on intelligent robots lead to organizational process innovation. Furthermore, indirect usefulness, such as organizational reputation, competitiveness, new business opportunities, and customer service improvement, which can be derived from the adoption of intelligent robots, can be helpful for process innovation. The results of this study are consistent with those found by Chau and Hui [14], and Iacovou et al. [15], which revealed that both direct and indirect benefits have a positive impact on process innovation in the context of service robots.

Second, industry and governmental pressure as environmental characteristics improve process innovation. These findings show that industry and governmental pressure are important to the business activities of enterprises, but enterprises cannot control these characteristics directly. Business partners, competitors, and unpredictable government policies often cause both types of pressures, which are uncontrollable. Although these are uncontrollable pressures, they are positive pressures for process innovation in an organization. In other words, one can see that intelligent robots can improve process innovation based on pressure factors, such as changes in related industry and government policies. Sometimes, an organization may have to innovate passively because of the impact of the surrounding environment. In this regard, Heidenreich and Kraemer [36] argued that passive innovation based on environmental pressure is not always negative. In other words, if an organization perceives that it does not recognize changes caused by environmental pressure or environmental change, it will have a positive impact on the organization if it attempts to innovate. These results are consistent with prior studies. For example, Joo and Kim [22] found that industrial and governmental pressure are deciding factors in the adoption of e-marketplace technology from an innovative theoretical perspective.

Finally, organizational supports have been shown to enhance the relationship between the direct and indirect usefulness of technical traits and process innovation based on intelligent robots. These results suggest that organizational support is an important variable that affects the relationship between the usefulness of IT and its acceptance. This is consistent with the results found by Lee et al. [26]. In other words, the direct and indirect usability of intelligent robots can improve process innovation to a greater degree if organizational support is provided during process innovation.

The findings of this study yield some important implications. First, we empirically analyzed a research model that attempts to explain process innovation based on intelligent robots using the TOE framework. The TOE framework examines how technological, organizational, and environmental factors affect innovation in an organization. In the field of IT, the TOE framework has been used as a base model for many studies that have had a significant impact on organizational process innovation, such as e-business, ERP, and RFID. Additionally, the TOE is known to be useful for explaining the factors affecting innovation and diffusion. This study has a significant theoretical implication in that it confirmed that the TOE framework is a model with sufficient explanatory power by applying it to research on process innovation based on intelligent robots, which is a recent issue.

Second, these results of empirical research on process innovation based on intelligent robots are presented at a time when intelligent robots are gaining significant attention and expanding into various industrial fields. Most studies on intelligent robots have focused on prospects from a technical perspective, such as market conditions, technology trend analysis, and robot industry 
outlook. However, this study included significant empirical analysis of SMEs introducing intelligent robots. Furthermore, national interest in robotics is growing very rapidly. According to a report released by the IT research firm Gartner in 2016, called the "Hype Cycle for Emerging Technologies", the robot market is currently in a transition period from the triggering stage to the high-expectation stage. Additionally, the International Federation of Robotics predicts that the robot market will grow at a double-digit compound annual growth rate over the next three years. From this point of view, this study suggests to managers at organizations that the introduction of intelligent robots will enhance innovation and advancement for domestic SMEs. Therefore, companies should cognize that the introduction of intelligent robots will have a significant impact on innovation outcomes.

The results of this study also have some practical implications. First, understanding and improving the accuracy, efficiency, and speed of work using intelligent robots has been found to improve process innovation. Additionally, the use of intelligent robots can help improve organizational competitiveness, image, and service to customers, which implies that companies can effectively use intelligent robots to innovate their processes. Finally, the use of intelligent robots can result in both tangible and intangible benefits, such as improving relationships with suppliers, improving price transparency and accessibility for customers, and lowering operational costs, even if the cost of technology investment is high. Therefore, it is necessary to recognize that making good use of intelligent robots can be beneficial to companies.

Second, industrial and governmental pressures on intelligent robots have an important impact on corporate process innovation. This means that if a business partner or competitor uses a new technology, such as an intelligent robot, other companies will have to accept that technology. Governmental policies or norms can also encourage companies to adopt and use new technology. Therefore, to revitalize the intelligent robot industry and enhance the competitiveness of a nation, it is necessary to prepare governmental policies that are appropriate to the current situation and properly support the related industries.

Finally, it was confirmed that process innovation could be accelerated and improved if sufficient resources are provided through organizational support when an organization intends to pursue process innovation based on intelligent robots. Therefore, companies that wish to pursue process innovation using intelligent robots should be sustained by appropriate supports, such as environmental initiatives, education, and financial and technical support, so that organization members can successfully implement new technologies in the organization.

Despite these implications, this study has some limitations that should be noted for future research. First, we proposed a limited number of external variables influencing process innovation based on intelligent robots. Therefore, future studies should review relevant literature and examine other non-technical factors within the TOE framework that lead to process innovation. Second, this study examined process innovation when using intelligent robots in SMEs. However, the environment for introducing robots may vary depending on the size and organizational structure of a company. Therefore, future studies could provide results that are more meaningful by comparing differences in organizational characteristics, such as organization size and industry.

Author Contributions: As the main contributors, M.J.C. and S.H.K. outlined and collected the data, conducted the first round of analysis and discussion, and performed the literature review. H.S.P. reorganized the manuscript, conducted an additional literature review, conceptualized the work, research design, and discussion, and completed a reference check.

Funding: This research was supported by Kyungpook National University Bokhyeon Research Fund, 2015.

Conflicts of Interest: The authors declare no conflicts of interest.

\section{References}

1. Chun, S.W. International and Korean Technology Trends for Intelligent Robots. Telecommun. Technol. Assoc. J. 2015, 158, 49-54.

2. Chung, W.J. Intelligent Robots in the IoT World. Entrue J. Inf. Technol. 2015, 14, 21-31. 
3. Carmines, E.G.; Zeller, R.A. Reliability and Validity Assessment; SAGE University Paper Series on Quantitative Applications in the Social Sciences, 07-017; Sage: Beverly Hills, CA, USA, 1979; ISBN 978-0803913714.

4. Vahid, M.; Luis, S.L.; Armando, J.P. Experience-Based Planning Domains: An Integrated Learning and Deliberation Approach for Intelligent Robots: Robot Task Learning from Human Instructions. J. Intell. Robot. Syst. 2016, 8, 3-4. [CrossRef]

5. Short, M.; Burn, K.A. Generic Controller Architecture for Intelligent Robotic Systems. Robot. Comput.-Integr. Manuf. 2011, 27, 292-305. [CrossRef]

6. Schumpeter, J.A. Capitalism, Socialism and Democracy; Harper and Row: New York, NY, USA, 1942; ISBN 9781135154752.

7. Damanpour, F. Innovation effectiveness, Adoption and Organizational Performance. In Innovation and Creativity at Work: Psychological and Organizational Strategies; West, M.A., Farr, J.L., Eds.; John Wiley \& Sons: New York, NY, USA, 1991; ISBN 978-0471926559.

8. Tarafdar, M.; Gordon, S.R. Understanding the Influence of Information Systems Competencies on Process Innovation: A Resource-Based View. J. Strateg. Inf. Syst. 2007, 16, 353-392. [CrossRef]

9. Knight, K.E. A Descriptive Model of the Intra-Firm Innovation Process. J. Bus. 1967, 10, 478-496. [CrossRef]

10. Barney, J.B.; Griffin, R.W. The Management of Organization: Strategy, Structure, Behavior; Houghton Mifflin: Boston, MA, USA, 1992; ISBN 0395574277.

11. Davenport, T.H. Process Innovation: Reengineering Work through Information Technology; Havard Business School Press: Boston, MA, USA, 1993; ISBN 0875843662.

12. Robey, D. Designing Organization; Irwin: Homewood, IL, USA, 1986; ISBN 0256033633.

13. Tornatzky, L.G.; Fleischer, M. The Processes of Technological Innovation; Lexington Books: Lexington, MA, USA, 1990; ISBN 0669203483.

14. Chau, P.Y.K.; Hui, K.L. Determinants of Small Business EDI Adoption: An Empirical Investigation. J. Organ. Comput. Electron. Commer. 2001, 11, 229-252. [CrossRef]

15. Iacovou, C.L.; Benbasat, I.; Dexter, A.S. Electronic Data Interchange and Small Organizations: Adoption and Impact of Technology. MIS Q. 1995, 19, 465-485. [CrossRef]

16. Chau, P.Y.K.; Tam, K.Y. Factors Affecting the Adoption of Open Systems: An Exploratory Study. MIS Q. 1997, 21. [CrossRef]

17. Kuan, K.K.Y.; Chau, P.Y.K. A Perception-Based Model for EDI Adoption in Small Businesses Using a Technology-Organization-Environment Framework. Inf. Manag. 2001, 38, 507-521. [CrossRef]

18. Yoon, T.E.; George, J.F. Why Aren't Organizations Adopting Virtual Worlds? Comput. Hum. Behav. 2013, 29, 772-790. [CrossRef]

19. Lin, H.F. Understanding the Determinants of Electronic Supply Chain Management System Adoption: Using the Technology-Organization-Environment Framework. Technol. Forecast. Soc. Chang. 2014, 86, 80-92. [CrossRef]

20. Lucas, H.C.; Swanson, E.B.; Zmud, R.W. Implementation, Innovation and Related Themes over the Years in Information Systems Research. J. Assoc. Inf. Syst. 2007, 8, 206-210. [CrossRef]

21. Han, S.H.; Lee, Y.C. An Empirical Study on TOE-Framework-Based factors for Motivation and Diffusion of PLM. e-Bus. Stud. 2008, 9, 363-391. [CrossRef]

22. Joo, Y.B.; Kim, Y.G. Determinants of Corporate Adoption of e-Marketplace: An Innovation Theory Perspective. J. Purch. Supply Manag. 2004, 10, 89-101. [CrossRef]

23. Davis, F.D. Perceived Usefulness, Perceived Ease of Use and User Acceptance of Information Technology. MIS Q. 1989, 13, 319-340. [CrossRef]

24. Lee, C.P.; Shim, J.P. An Exploratory Study of Radio Frequency Identification (RFID) Adoption in the Healthcare Industry. Eur. J. Inf. Syst. 2007, 16, 712-724. [CrossRef]

25. Zhu, K.; Dong, S.; Xu, S.X.; Kraemer, K.L. Innovation Diffusion in Global Contexts: Determinants of Post-Adoption Digital Transformation of European Companies. Eur. J. Inf. Syst. 2006, 15, 601-616. [CrossRef]

26. Lee, H.Y.; Lee, Y.K.; Kwon, D. The Intention to Use Computerized Reservation Systems: The Moderating Effects of Organizational Support and Supplier Incentive. J. Bus. Res. 2005, 58, 1552-1561. [CrossRef]

27. Ramdani, B.; Kawalek, P.; Lorenzo, O. Predicting SME's Adoption of Enterprise Systems. J. Enterp. Inf. Manag. 2009, 22, 10-24. [CrossRef]

28. Malhotra, M.; Heine, M.; Grover, V. An Evaluation of the Relationship between Management Practices and Computer Aided Design Technology. J. Oper. Manag. 2001, 19, 307-333. [CrossRef] 
29. Venkatesh, V.; Davis, F.D. A Model of the Antecedents of Perceived Ease of Use: Development and Test. Decis. Sci. 1996, 27, 451-481. [CrossRef]

30. Igbaria, M.; Zinatelli, V.; Cragg, P.; Cavaya, A.L.M. Personal Computing Acceptance Factors in Small Firms: A Structural Equation Model. MIS Q. 1997, 21, 279-305. [CrossRef]

31. Hsu, C.J.; Lee, N.; Straub, D.W. Institutional Influences on Information Systems Security Innovations. Inf. Syst. Res. 2012, 23, 1-22. [CrossRef]

32. Liang, H.; Saraf, N.; Hu, Q.; Xue, Y. Assimilation of Enterprise Systems: The Effect of Institutional Pressures and the Mediating Role of Top Management. MIS Q. 2007, 31, 59-87. [CrossRef]

33. Lazarus, I.R.; Novicoff, W.M. Six Sigma Enters the Healthcare Mainstream. Manag. Healthc. Exec. 2004, 4, 26-32.

34. Fornell, C.; Larcker, D.F. Evaluating Structural Equation Models with Unobservable Variables and Measurement Error. J. Mark. Res. 1981, 18, 39-50. [CrossRef]

35. Eisenberger, R.; Huntington, R.; Hutchison, S.; Sowa, D. Perceived Organizational Support. J. Appl. Psychol. 1986, 71, 500-507. [CrossRef]

36. Heidenreich, S.; Kraemer, T. Passive Innovation Resistance: The Curse of Innovation? Investigating Consequences for Innovative Consumer Behavior. J. Econ. Psychol. 2015, 51, 134-151. [CrossRef]

(C) 2018 by the authors. Licensee MDPI, Basel, Switzerland. This article is an open access article distributed under the terms and conditions of the Creative Commons Attribution (CC BY) license (http:/ / creativecommons.org/licenses/by/4.0/). 